\title{
Factors Conditioning the Adherence to Pharmacological Prescription in Patients with Hypertension Attending Primary Healthcare Units in Quito - Ecuador
}

\author{
By Patricia Ortiz Solórzano, Karen Pesse-Sorensen \\ \& Victor Hugo Mena Maldonado \\ Pontifical Catholic University of Ecuador
}

Abstract- Low adherence to pharmacological treatment in patients diagnosed with hypertension is related to poor blood pressure control and an increased incidence of cardiovascular complications and deaths. A cross-sectional study was performed to determine conditioning factors towards adherence. Questionnaires and clinical evaluations were applied to 187 patients attending three first-level health units; in 130 of them laboratory tests were carried out. Diagnostic criteria were based on the European Clinical Practice Guidelines; adherence was based on the Morinsky test. 57.1\% of patients had blood pressure values above the controlled threshold, and $71.1 \%$ reported non-adherence to pharmacological prescription. Factors associated whit low adherence were coexisting moderate to severe depression (OR $=2,054 ; \mathrm{Cl} 1,064-3,964)$, low educational level (3.75 \pm 3.05 years), poor understanding of medical prescriptions $(\mathrm{OR}=2.3 \mathrm{Cl} 1.188-4.477)$, irregular supply and limited economic access to prescribed drugs $((\mathrm{OR}=1.97 \mathrm{Cl} 1.08-3.817)$, and low satisfaction with the care offered at health services $(\mathrm{OR}=$ 2.45; Cl 1.202-5.00).

Keywords: medication adherence; hypertension; risk factors; primary health care.

GJMR-I Classification: NLMC Code: QV 4

Strictly as per the compliance and regulations of:

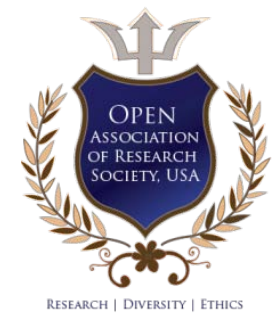

(C) 2021. Patricia Ortiz Solórzano, Karen Pesse-Sorensen \& Victor Hugo Mena Maldonado. This research/review article is distributed under the terms of the Attribution-NonCommercial-NoDerivatives 4.0 International (CC BY-NC-ND 4.0). You must give appropriate credit to authors and reference this article if parts of the article are reproduced in any manner. Applicable licensing terms are at https://creativecommons.org/licenses/by-nc-nd/4.0/. 


\title{
Factors Conditioning the Adherence to Pharmacological Prescription in Patients with Hypertension Attending Primary Healthcare Units in Quito - Ecuador
}

\author{
Patricia Ortiz Solórzano ${ }^{\alpha}$, Karen Pesse-Sorensen ${ }^{\circ} \&$ Victor Hugo Mena Maldonado ${ }^{\circ}$
}

\begin{abstract}
Low adherence to pharmacological treatment in patients diagnosed with hypertension is related to poor blood pressure control and an increased incidence of cardiovascular complications and deaths. A cross-sectional study was performed to determine conditioning factors towards adherence. Questionnaires and clinical evaluations were applied to 187 patients attending three first-level health units; in 130 of them laboratory tests were carried out. Diagnostic criteria were based on the European Clinical Practice Guidelines; adherence was based on the Morinsky test. $57.1 \%$ of patients had blood pressure values above the controlled threshold, and $71.1 \%$ reported non-adherence to pharmacological prescription. Factors associated whit low adherence were coexisting moderate to severe depression $(\mathrm{OR}=2,054 ; \mathrm{Cl} 1,064$ - 3,964), low educational level (3.75 \pm 3.05 years), poor understanding of medical prescriptions (OR $=2.3 \mathrm{Cl} 1.188-4.477$ ), irregular supply and limited economic access to prescribed drugs $((\mathrm{OR}=1.97 \mathrm{Cl} 1.08-3.817)$, and low satisfaction with the care offered at health services $(O R=$ 2.45; Cl 1.202-5.00).
\end{abstract}

Keywords: medication adherence; hypertension; risk factors; primary health care.

\section{INTRODUCTION}

$\mathrm{H}$ ypertension (HTN) constitutes a public health problem and represents the core risk factor for premature death worldwide (Chow \& Gupta, 2019; GBD 2017 Risk Factor Collaborators, 2018). Its control depends directly on the quality and timeliness of the medical diagnosis, treatment, and follow-up of the individual patient and effective health systems (Marrugat et al., 2003). Given that cheap and effective antihypertensive treatments are available, hypertension control and prevention of the morbidity and mortality that

Corresponding Author a: Pontifical Catholic University of Ecuador (Pontificia Universidad Católica del Ecuador), Faculty of Medicine, Quito, Ecuador; Universidad Autónoma de Barcelona, Barcelona, Spain. Department of Pediatrics, Obstetrics and Gynecology and Preventive Medicine.e-mail: portizs@puce.edu.ec

Author o: Pontifical Catholic University of Ecuador (Pontificia Universidad Católica del Ecuador), Faculty of Medicine, Quito, Ecuador.e-mail:kpesse@puce.edu.ec

Author $\rho$ : Pontifical Catholic University of Ecuador (Pontificia Universidad Católica del Ecuador), Faculty of Medicine, Quito, Ecuador.e-mail:vmenam@puce.edu.ec it generates should be achievable (Chow et al., 2013; McAlister et al., 2011). However, even in high-income countries, a significant proportion of people with hypertension do not know their diagnosis, and among those who do, a minority have been treated and have appropriate control (Maimaris et al., 2013; Pereira et al., 2009). Worldwide, it is estimated that only one in seven people have their pressure under control, that is, a blood pressure (BP) less than 140/90 mm Hg. Some of the obstacles that have been described to achieve BP control are the absence of comprehensive health services at the primary care level, limited access to drugs, and failure of health systems to effectively manage the prevention and treatment of the disease (MacMahon et al., 2008; Patel et al., 2016).

Available literature shows a clear correlation between a low level of adherence and less blood pressure control. Additionally, it has been associated with adverse outcomes such as cerebrovascular accidents, heart failure, myocardial infarction, and death. Impaired adherence constitutes a critical barrier for the reduction of blood pressure (Gosmanova \& Kovesdy, 2015; Peacock \& Krousel-Wood, 2017). However, the rates of adherence to medical prescriptions by patients with chronic conditions are very low. It is estimated that between $20-50 \%$ of patients suffering from these diseases do not take their medication as prescribed. An even larger number do not comply with the indications on changes in lifestyle (Kripalani et al., 2007). In the case of HTN, evidence shows that it affects 30 to $65 \%$ of patients and that $87.3 \%$ of uncontrolled patients presented failures in adherence to medical prescription (Abegaz et al., 2017). Because to its consequences on the health status, such as therapeutic failures, increased hospitalization rates, and increased healthcare costs, the WHO considers low adherence a priority public health issue (World Health Organization, 2004).

Lack of adherence is multidimensional. The factors that contribute to its existence are categorized into those related to the patient, such as socioeconomic status, inadequate knowledge of the disease, and costs of medication, and those related to the health system 
and equipment. Additionally, there are factors related to the treatment itself and those related to the disease (World Health Organization, 2004). It is necessary to study the adherence to prescription, as well as the main factors that condition compliance with medical indications, in particular those related to deficiencies in the quality of care provided by health services to hypertensive patients and their consequences on the morbidity and mortality caused by HTN.

The objective of this study was to determine the factors related to the patient, their clinical status, and the health services that facilitate or limit the adequate adherence to pharmacological treatment of patients who attend first-level health units in the South of Quito.

\section{il. Methods and Procedures}

\section{a) Study Design}

This research is a cross-sectional study carried out between February and November 2012 by the Faculty of Medicine of the Pontifical Catholic University of Ecuador (PUCE) and the University of Michigan. The Research Bioethics Committee of the Pontifical Catholic University of Ecuador (PUCE) and the Central University of Ecuador (Universidad Central del Ecuador) approved the study protocol. The Ministry of Public Health of Ecuador also approved the project.

\section{b) Research scope and subjects}

Study universe corresponded to all patients with diagnosed hypertension who regularly attended the health services belonging to the Ministry of Public Health of the District of Guamaní. This District is located in a suburban area south of the city of Quito; it serves 51,986 direct beneficiaries, 99,143 indirect beneficiaries with a total of 151,129 beneficiaries: Health care is covered by a type $\mathrm{C}$ Health Center and by type $\mathrm{A}$ and $\mathrm{B}$ health services. Three units were intentionally selected: the Guamaní Health Center, which, as the main center of the area, brings together the biggest number of patients with HTN. The Social Assistance Health Sub center that has the highest number of hypertensive patients registered in the health units attached to the area; and the Pueb/o Unido health sub-center; where a family doctor works and provides care and follow-up to patients and their families with a comprehensive health approach.

Sampling was not carried out since all patients registered in these three units were included in the research, given they could be located and voluntarily agreed to participate in the study. The total number of patients with HTN registered in the units was 298, of which 188 (63.1\%) participated in the study; one survey was eliminated due to incomplete information, thus $n=$ 187.

\section{c) Data collection}

A questionary that included sociodemographic information and information on the diagnosis, control, and follow-up by the health services of each patient was applied. A clinical evaluation including taking, recording, and classification of blood pressure values was carried out following the recommendations of the JNC-7 (DEPARTMENT OF HEALTH AND HUMAN, 2003); as well as anthropometric measurements (weight, height, abdominal circumference), assessment of cardiovascular risk and cognitive ability through the application of the Minimental test. Medical students from PUCE and the University of Michigan who received training and supervision from a faculty professor performed these procedures.

A subsample of the 130 patients who accepted the procedure had their blood glucose, cholesterol and creatinine determined. The samples were collected and analyzed by technicians from the PUCE clinical laboratory (DISERLAB) following international recommendations on biosafety and blood transport.

The criteria for evaluating the clinical status of the patient were established based on the European HTN Clinical Practice Guide (CPG) (ESH / ESC, 2013), which considers controlled hypertension when blood pressure values are $\leq 140 / 90 \mathrm{mg} / \mathrm{mm}$ and overweight or obesity when $\mathrm{BMI} \geq 25$. Fasting blood glucose $<101$ $\mathrm{mg} / \mathrm{dl}$ was classified as normal, $102-125 \mathrm{mg} / \mathrm{dl}$ as altered and $\geq 126 \mathrm{mg} / \mathrm{dl}$ as diabetes; creatinine values to normal, altered renal function were $\geq 1.3 \mathrm{mg} / \mathrm{dl}$ in men and $1.2 \mathrm{mg} / \mathrm{dl}$ in women; and the total cholesterol level was considered elevated when the values were $190 \mathrm{mg} / \mathrm{dl}$.

Treatment adherence defined as compliance with the pharmacological indications, both in dose and schedule and complete consumption of the medication, was self-reported, based on the Morinsky test (Morisky et al., 1986), considering as "adherent" those patients who fully complied with all the indications in the two evaluated dimensions.

\section{d) Information Analysis}

For the statistical analysis, a database was generated in Excel, and quality control of the information was carried out. It was then imported into the SPSS v 18.0 program. The statistical analysis initially included descriptive statistics: the mean, median, mode, and standard deviation values of the quantitative variables such as Glucose, Creatinine, Cholesterol, BMI, and Creatinine Clearance values were determined. Percentages were calculated for the qualitative variables. Subsequently, a bivariate analysis was performed, using the OR as association measures and the Chi-square as a significance test for qualitative variables. For quantitative variables, the Kolmogorov normality test was applied to establish the test to be used for the difference in means, be it the Student's t or 
the Mann-Whitney U; finally, a multiple regression model was performed.

\section{Results}

The demographic and clinical characteristics of the study population are described in Table 1. The mean age was 63.8 years (SD 12.7) with a range of 35 to 89 years; the proportion of women was higher $(83.4 \%)$ than that of men. Patients reported a low level of education with an average of 4.27 (SD 3.38) years completed. Regarding the clinical status of the patients who underwent laboratory tests $(n=130)$, it should be noted that more than $60 \%$ had hypercholesterolemia, $8.5 \%$ diabetes, $2.3 \%$ altered kidney function; and $86.5 \%$ were overweight or obese. $57.1 \%$ of patients had an uncontrolled blood pressure value.

a) Medication Adherence and its conditioning factors

$28.9 \%$ (95\% Cl: $22.4 \%-35.4 \%)$ of the patients reported good adherence to the drug prescription, while $71.1 \%$ (95\% Cl: $64.6 \%-77,6 \%)$ were non-adherent.

Table 2 shows the sociodemographic characteristics of the patients and their relationship with low adherence. Age $(O R=0.98)$; $\operatorname{sex}(O R=0.69)$, living alone $(\mathrm{OR}=0.79)$, having a partner $(\mathrm{OR}=1.36)$ or working $(\mathrm{OR}=1.28)$, were not statistically significantly associated with adherence to pharmacological treatment. In contrast, the average number of years of formal education completed was significantly lower in non-adherent patients $(3.75 \pm 3.05$ years) than in adherent patients (5.65 \pm 3.7 years). Factors related to self-care, such as referring to carrying out actions and the need for another person's assistance for this purpose, were not significantly associated with adherence. However, the proportion of non-adherence was higher in patients who reported performing these actions (69.2\%) or perceiving the need to do so $74.8 \%$, with ORs of 1.25 and 1.48 , respectively.

Table 3 presents the factors related to the patient's clinical status, showing that there are no significant differences between adherents and nonadherents in terms of the presence or absence of hypercholesterolemia, diabetes, being overweight or obese, or with the cognitive status of the patient. However, people who presented moderate or severe depression showed a higher risk of non-adherence than those without this health problem $(\mathrm{OR}=2,054 ; \mathrm{Cl} 1,064$ - 3,964).

\section{b) Conditioning Factors for Adherence Related to} Health Services

Table 4 presents the conditioning factors for adherence related to the organization and operation of health services.

The need for help in reading medical indications was greater among the non-adherent, but the difference with the adherent subjects was not statistically significant. That doctors inquire about adherence and that the patient understands the prescribed medications, disrespect for patients' opinions by health professionals, and not shared goal setting with patients, were also not associated in a statistically significant degree with adherence. Regarding the indications written by the doctor or nurse, it was found that patients who reported having little or no understanding of these had a higher risk of non-adherence $(\mathrm{OR}=2.3 \mathrm{Cl} 1.188$ 4.477) than those who did understand them. The irregular and incomplete supply of drugs by health units also constituted a risk factor for low adherence (OR = $1.93 \mathrm{Cl} 1.022-3.74)$. Difficulty in accessing prescribed drugs due to lack of economic means increased the risk of not complying with treatment $(\mathrm{OR}=5.715$; $\mathrm{Cl} 2.85$ 11.43). The perception of patients about disrespect for their beliefs (OR $=1.97 \mathrm{Cl} 1.08-3.817$ ) and the little or no satisfaction of patients with health services $(O R=$ 2.45; Cl 1.202-5.005) were also related to low adherence to pharmacological indications.

The logistic regression model (Table 5) shows that factors that constitute facilitators of adequate adherence were higher education level, having economic means to access the prescribed medications, respect for patient's beliefs, and patient satisfaction with health services.

Even though non-adherents had a higher proportion of inadequate blood pressure control, the difference with adherents was not statistically significant $(p=0.081)$; see table 6 .

\section{Discussion}

The present study contributes to the understanding of the obstacles to adherence to their pharmacological indications in patients with HTN seen at the first level of care. Collected data showed that seven out of ten hypertensive patients were nonadherent to the prescribed drug treatment, and more than half of the patients had inadequate blood pressure control. In addition, about three-quarters of the patients were obese or overweight, $60 \%$ had hypercholesterolemia, and $21 \%$ had moderate to severe cognitive impairment. However, no association was found between low adherence and inadequate control of hypertension or an impaired clinical status, except that patients with moderate or severe depression were less compliant. Regarding patient-related factors linked to poor adherence, the low level of education (average years of formal education completed) stands out. Regarding health services, it was found that poor understanding of medical indications, irregular supply of medicines, reduced access to affordable drugs, and low level of satisfaction with health services increased the possibility of poor adherence.

Reduced adherence to medical indications in general, and pharmacological prescription in particular, 
is a highly prevalent problem in the care of patients with chronic diseases and represents a priority for public health (Patel et al., 2016; Peacock \& Krousel-Wood, 2017). In patients with hypertension poor adherence has been associated with lesser blood pressure control, cardiovascular complications, and death (Burnier \& Egan, 2019; Gosmanova \& Kovesdy, 2015). In the United States, an estimated 125,000 annual deaths and $33 \%$ to $69 \%$ of hospital admissions are due to poor adherence (Bosworth et al., 2011). Regarding health systems treatment failure increases hospitalization rates and health costs (World Health Organization, 2004). Therefore, timely detection and correction of low adherence should be part of the care and follow-up of patients with chronic diseases.

This study did not show a statistically significant association between non-adherence and poor blood pressure control. However, the proportion of nonadherence was higher in uncontrolled patients (61\%). Other studies have shown that non-adherence is the key factor for uncontrolled blood pressure (Burnier \& Egan, 2019; van der Laan et al., 2017); non-adherence increases significantly in uncontrolled patients (from 45.2\% to 87.3\%) (Abegaz et al., 2017). Lor Maichou et al. (Lor et al., 2019) asserts that adherence above $80 \%$ to antihypertensive medication is essential for optimal blood pressure control.

WHO estimates that the prevalence of nonadherence to antihypertensive drug treatment worldwide ranges from 30 to $50 \%$ (World Health Organization, 2004). In the study by Zullig (Zullig et al., 2015), nonadherence was $58.1 \%$, and in that of Lor (Lor et al., 2019), non-adherence was $88.4 \%$. A systematic review of 28 studies carried out in 15 countries shows a prevalence of non-adherence of $45.2 \%$ (Abegaz et al., 2017), and the research by Steiner (2009) found a mean therapeutic adherence of $70 \%$, where only $36 \%$ obtained more than $80 \%$ of the prescription drugs. Adherence rates in patients with hypertension are very diverse, and the magnitudes reported in the different studies cannot be compared due to the use of various indicators and measurement instruments. However, the default value found in this study $(71.1 \%)$ may indicate of the gap that exists between high and low and middle-income countries.

Lack of adherence is a complex, multifactorial problem; its conditioning factors can be classified according to their relations with the pathology, the patient, the health system, the doctor-patient relationship, or with the treatment itself (Khatib et al., 2014; van der Laan et al., 2017). In this study, there was no association between demographic factors such as sex, ethnicity, or age of the patient. While some research has found that men are less adherent than women, that evidence is conflicting. The study "Cohort Study of Medication Adherence among Older Adults (CoSMO)" (M. Krousel-Wood et al., 2011) reported very low adherence to medication (14\%) in patients older than 65 years of age; these values vary according to age group, sex, and ethnicity (MA Krousel-Wood et al., 2009). In the present study, patients with lower education had lower adherence, which corroborates what was reported by other studies in which a low level of education and reduced knowledge about the disease and treatment were significantly associated with low adherence (Parra et al. al., 2019).

International evidence suggests that clinical conditions, and in particularly cognitive dysfunction and mental health problems, constitute relevance obstacles for adherence (Steiner et al., 2009; Zullig et al., 2015). In this study, no significant association was found between hypercholesterolemia, excess weight or obesity, and low adherence. However, the coexistence of hypercholesterolemia and hypertension is common: Tadick \& Cuspide found that $69.7 \%$ of hypertensive patients presented hypercholesterolemia.

This study shows that the presence of moderate/severe depression constitutes a risk factor for non-adherence; these results are similar to those reported by (M. Krousel-Wood et al., 2011; Lor et al., 2019), who found that depressed people with chronic diseases are more likely to not comply with the prescribed treatment. Therefore, doctors should carry out a timely detection and adequate treatment of depression, especially in patients with poor adherence and poor blood pressure control.

Ecuador has made great efforts to implement comprehensive reforms and a public policy aimed to regulate health care (Espinosa, 2017), this does not guarantee compliance at the local level. Free access to care in public health services and the formulation of plans and programs aimed at providing permanent and timely access to comprehensive health care, based on the principles established in the Constitution (Constitution of the Republic of Ecuador, 2008), have not always crystallized in benefits provided to patients with chronic diseases who are cared for at the first level. Different authors report an association between low adherence with the following factors of the health care system: not being able to read the written instructions regarding the management of the disease, not receiving information about hypertension, no availability of out-ofpocket expenses to access care and medications, deficiencies in the relationship and communication between patient and their healthcare provider, in addition to a general patient's perception of receiving poor quality of care (Parra et al., 2019; van der Laan et al., 2017).

To reduce the risk and burden of morbidity and mortality from cardiovascular diseases in low or medium per capita income countries WHO proposes different strategies to improve control, monitoring, and follow-up of hypertensive patients. The main recommendation is to strengthen actions to improve the levels of 
knowledge, treatment, and control of hypertension, emphasizing the timely detection, selection, and appropriate use of medications and therapeutic adherence (World Health Organization, 2013). The challenge for many health systems is to seek strategies that reduce detected deficiencies, such as failures in the follow-up and the coordination in care, and patients receiving insufficient information that leads them to have difficulties in self-managing their disease (Samb et al., 2010). It is essential to improve patient follow-up and provide quality care in medical consultation, as it constitutes an opportunity to make clinical decisions based on blood pressure values and at the same time, provide counseling and evaluate adherence to treatment (Zuo et al., 2019).

In the clinical management of hypertension, patients are in charge of 95\% of their daily care. Although this self-care goes beyond taking the prescribed medication, this aspect being the least complicated, it is vital to guarantee control of blood pressure levels (Comarca, 2011). Ultimately, adherence to the pharmacological prescription corresponds to patients' decision and autonomy; however, health services have a relevant role to play to help them have better compliance to medical prescription. Establishing effective channels of communication between health providers and their patients, which can help to understand the disease and the treatment by the latter, as well as share decision-making regarding the clinical management, are key conditioning factors to achieve this goal (Martínez C. et al., 2016; World Health Organization, 2013).

This study has the following limitations: it was carried out in a specific area of the Metropolitan District of Quito and one Type- C and two Type-A healthcare units belonging to the Ministry of Health; therefore, it cannot be generalized to all health services in Quito. Self-reporting was used in several of the indicators, especially in adherence. Additional questions were included in the Morinsky test to have more information on adherence, but this limits its international comparability. People who refused to take one of the tests represented up to $6 \%$ of the non-adherent subsample.

\section{Conclusions}

The efficacy of antihypertensive medications in controlling blood pressure and reducing adverse outcomes in morbidity and mortality from cardiovascular diseases is well documented. However, patient's adherence to the pharmacological treatment prescribed by the health professional plays a central role in achieving the objectives for adequate clinical management of this disease. The factors that determine the low adherence are multidimensional; in the present study, the logistic regression model showed that higher educational level and having the economic means to access drugs represent factors that facilitate compliance with the pharmacological prescription. Regarding the healthcare services and team, the main conditioning factors for adherence are respect for the beliefs of patients and patient satisfaction with health services. Comprehensive strategies should be implemented for the management of hypertension, improving patient follow-up, not only about blood pressure control but also through the implementation of locally adapted strategies aimed at improving the clinical condition of patients and their quality of life.

\section{ACKNOWLEDGMENTS}

The authors thank Dr. Monserrat Martin for reviewing the draft of the manuscript and offering her comments and contributions. We also thank the students from the Pontifical Catholic University of Ecuador and the University of Michigan who participated in the data collecting process.

\section{Funding}

This research received funding from the Pontifical Catholic University of Ecuador (Pontificia Universidad Católica del Ecuador). 
Table 1: General Characteristics of the Study Population

\begin{tabular}{|c|c|c|}
\hline Sociodemographic & Frequency or Mean & Percentage or SD \\
\hline Age & $63.8(\tilde{x})$ & 12.7 (SD) \\
\hline \multicolumn{3}{|l|}{ Level of education } \\
\hline Years approved & $4,27\left(x^{\tilde{x}}\right)$ & 3,38 (SD) \\
\hline \multicolumn{3}{|l|}{ Sex } \\
\hline Female & 156 & 83.4 \\
\hline Male & 31 & 16.6 \\
\hline \multicolumn{3}{|l|}{ Marital Status } \\
\hline No partner & 79 & 42.0 \\
\hline With partner & 108 & 57.8 \\
\hline \multicolumn{3}{|l|}{ Employment } \\
\hline Yes & 51 & 27.4 \\
\hline No & 135 & 72.6 \\
\hline \multicolumn{3}{|l|}{ Clinical Status } \\
\hline \multicolumn{3}{|l|}{ Cholesterol } \\
\hline Normal & 46 & 35,4 \\
\hline Elevated & 84 & 64,6 \\
\hline \multicolumn{3}{|l|}{ Blood Glucose } \\
\hline Normal & 109 & 83,8 \\
\hline Altered & 10 & 7,7 \\
\hline Diabetes & 11 & 8,5 \\
\hline \multicolumn{3}{|l|}{ Creatinine (renal dysfunction) } \\
\hline Yes & 3 & 2,3 \\
\hline No & 127 & 97,7 \\
\hline \multicolumn{3}{|l|}{ BMI } \\
\hline Normal & 25 & 13,5 \\
\hline Overweight/Obesity & 160 & 86,5 \\
\hline \multicolumn{3}{|l|}{ Cognitive impairment } \\
\hline Mild & 143 & 79 \\
\hline Moderate & 38 & 21 \\
\hline \multicolumn{3}{|l|}{ Depression } \\
\hline Minimal/mild & 61 & 67,2 \\
\hline Moderate/severe & 125 & 32,8 \\
\hline \multicolumn{3}{|l|}{ Hypertension } \\
\hline Uncontrolled & 78 & 42,9 \\
\hline Controlled & 104 & 57,1 \\
\hline
\end{tabular}


Table 2: Pacient'S Factors Associated with Medication Adherence

\begin{tabular}{|c|c|c|c|c|c|c|c|}
\hline \multirow{2}{*}{$\begin{array}{l}\text { Demographic } \\
\text { characteristics }\end{array}$} & \multicolumn{2}{|c|}{ Non adherents $(n=133)$} & \multicolumn{2}{|c|}{ Adherents $(n=54)$} & \multirow[t]{2}{*}{ OR } & \multirow[t]{2}{*}{$\mathrm{Cl} 95 \%$} & \multirow[t]{2}{*}{$p$-Value } \\
\hline & Frequency & Percentage & Frequency & Percentage & & & \\
\hline $\begin{array}{l}\text { Age } \\
\leq 65 \text { years } \\
>65 \text { years }\end{array}$ & $\begin{array}{l}69 \\
64\end{array}$ & $\begin{array}{l}71,9 \\
70,3\end{array}$ & $\begin{array}{l}27 \\
27\end{array}$ & $\begin{array}{l}28,1 \\
29,7\end{array}$ & 0,98 & $\begin{array}{c}0,43- \\
1,74\end{array}$ & 0,816 \\
\hline $\begin{array}{l}\text { Sex } \\
\text { Male } \\
\text { Female }\end{array}$ & $\begin{array}{c}20 \\
113\end{array}$ & $\begin{array}{l}64.5 \\
72,4\end{array}$ & $\begin{array}{l}11 \\
43\end{array}$ & $\begin{array}{l}35.5 \\
27,6\end{array}$ & 0,692 & $\begin{array}{c}0,306- \\
1,56\end{array}$ & 0,374 \\
\hline $\begin{array}{l}\text { Living with } \\
\text { Alone } \\
\text { Family }\end{array}$ & $\begin{array}{c}10 \\
123\end{array}$ & $\begin{array}{l}66,7 \\
71,5\end{array}$ & $\begin{array}{c}5 \\
49\end{array}$ & $\begin{array}{l}33,3 \\
28,5\end{array}$ & 0,797 & $\begin{array}{c}0,259- \\
2,45\end{array}$ & $0,768^{*}$ \\
\hline $\begin{array}{l}\text { Marital status } \\
\text { No partner } \\
\text { With partner }\end{array}$ & $\begin{array}{l}59 \\
74 \\
\end{array}$ & $\begin{array}{l}74,7 \\
68,5 \\
\end{array}$ & $\begin{array}{l}20 \\
34\end{array}$ & $\begin{array}{l}25,3 \\
31,5\end{array}$ & 1,355 & $\begin{array}{c}0,708- \\
2,59\end{array}$ & 0,358 \\
\hline $\begin{array}{l}\text { Employment } \\
\text { Yes } \\
\text { No }\end{array}$ & $\begin{array}{l}38 \\
94\end{array}$ & $\begin{array}{l}74,5 \\
69,6\end{array}$ & $\begin{array}{l}13 \\
41\end{array}$ & $\begin{array}{l}25,5 \\
30,4\end{array}$ & 1,275 & $\begin{array}{c}0,615- \\
2,64\end{array}$ & 0,513 \\
\hline $\begin{array}{l}\text { Education } \\
\text { (years } \\
\text { approved) } \\
\text { Mean } \\
\text { SD }\end{array}$ & $\begin{array}{l}3,75 \\
3,05\end{array}$ & & $\begin{array}{c}5,65 \\
3,7\end{array}$ & & & & $0,001^{* *}$ \\
\hline $\begin{array}{l}\text { Impaired family } \\
\text { economy } \\
\text { Yes } \\
\text { No }\end{array}$ & $\begin{array}{l}93 \\
40\end{array}$ & $\begin{array}{c}76,2 \\
62,5 \%\end{array}$ & $\begin{array}{l}29 \\
24\end{array}$ & $\begin{array}{c}23,8 \\
37,5 \%\end{array}$ & 1,924 & $\begin{array}{c}0,99- \\
3,70\end{array}$ & 0,049 \\
\hline Selfcare & & & & & & & \\
\hline $\begin{array}{l}\text { Routine care } \\
\text { Few or nothing } \\
\text { Often/always }\end{array}$ & $\begin{array}{l}73,7 \\
69,2\end{array}$ & $\begin{array}{l}20 \\
33\end{array}$ & & $\begin{array}{l}26,3 \\
30,8\end{array}$ & 1,249 & $\begin{array}{c}0,64- \\
2,40\end{array}$ & 0,50 \\
\hline $\begin{array}{l}\text { Support care } \\
\text { Yes } \\
\text { No }\end{array}$ & $\begin{array}{l}80 \\
52\end{array}$ & $\begin{array}{l}74,8 \\
66,7\end{array}$ & $\begin{array}{l}27 \\
26\end{array}$ & $\begin{array}{l}25,2 \\
33,3\end{array}$ & 1,481 & $\begin{array}{c}0,780- \\
2,815\end{array}$ & 0,22 \\
\hline
\end{tabular}

Note: Some questions were not answered, they were considered as missing data. Thus, frequencies not always total the number of subjects included in the sample

Table 3: Factors Related to Patient'S Clinical Status Associated Whit Adherence to Medication

\begin{tabular}{|c|c|c|c|c|c|c|c|}
\hline \multirow[t]{2}{*}{ Clinical features } & \multicolumn{2}{|c|}{ Non-adherents } & \multicolumn{2}{|c|}{ Adherents } & \multirow[t]{2}{*}{ OR } & \multirow[t]{2}{*}{$\mathrm{Cl} 95 \%$} & \multirow[t]{2}{*}{$p$-value } \\
\hline & Frequency & Percentage & Frequency & Percentage & & & \\
\hline \multicolumn{8}{|l|}{ Cholesterol } \\
\hline Elevated & 56 & 66,7 & 28 & 33,3 & 0,875 & $0,403-1,899$ & 0,735 \\
\hline Normal & 32 & 69,6 & 14 & 30,4 & & & \\
\hline \multicolumn{8}{|l|}{ Blood glucose } \\
\hline Normal & 70 & 64,2 & 39 & 35,8 & & & \\
\hline Altered & 9 & 90,0 & 1 & 10,0 & & & 0,144 \\
\hline Diabetes & 9 & 81,8 & 2 & 18,2 & & & \\
\hline \multicolumn{8}{|l|}{ BMI } \\
\hline Normal & 17 & 68 & 8 & 32 & 0,832 & $0,335-$ & 0,690 \\
\hline Overweight/Obesity & 115 & 71,9 & 45 & 28,1 & & 2,062 & \\
\hline \multicolumn{8}{|l|}{ Cognitive impairment } \\
\hline Mild & 99 & 69,2 & 44 & 30,8 & & & \\
\hline Moderate & 29 & 76,3 & 9 & 23,7 & 0,698 & $0,305-1,598$ & 0,431 \\
\hline \multicolumn{8}{|l|}{ Depression } \\
\hline Moderate/severe & 95 & 76,0 & 30 & 24,0 & 2,054 & $1,064-3,964$ & 0,030 \\
\hline Mild & 37 & 60,7 & 24 & 39,3 & & & \\
\hline
\end{tabular}

Note: Some questions were not answered, they were considered as missing data. Thus, frequencies not always total the number of subjects included in the sample. 
Table 4: Factors Related to Health Services Associated Whit Medication Adherence

\begin{tabular}{|c|c|c|c|c|c|c|c|}
\hline \multirow[t]{2}{*}{ Medical care } & \multicolumn{2}{|c|}{$\begin{array}{l}\text { Non-adherents } \\
\quad(n=133)\end{array}$} & \multicolumn{2}{|c|}{ Adherents $(n=54)$} & \multirow[t]{2}{*}{ OR } & \multirow[t]{2}{*}{$\mathrm{Cl} 95 \%$} & \multirow[t]{2}{*}{$\begin{array}{c}\mathrm{p}- \\
\text { value }\end{array}$} \\
\hline & Frequency & Percentage & Frequency & Percentage & & & \\
\hline \multicolumn{8}{|l|}{$\begin{array}{l}\text { Understanding } \\
\text { written prescription }\end{array}$} \\
\hline Few or nothing & 98 & 76,6 & 30 & 23,4 & 2,306 & $1,188-4,477$ & 0,013 \\
\hline Very good /excellent & 34 & 58,6 & 24 & 41,4 & & & \\
\hline Help to read & & & & & & & \\
\hline instructions & 74 & 67,3 & 36 & 32,7 & 0,638 & $0,329-1,237$ & 0,182 \\
\hline \multicolumn{7}{|l|}{ Always/often } & \\
\hline Health services & & & & & & & \\
\hline providing & & 7 & & & & & \\
\hline prescripted & & & & & 102 & 102037 & $0 \cap 1$ \\
\hline pharmaceuticals & $\begin{array}{l}84 \\
43\end{array}$ & 5,1 & 27 & 24,3 & 1,93 & $1,022-3,14$ & 0,041 \\
\hline Always & & & & & & & \\
\hline \multirow{2}{*}{\multicolumn{8}{|c|}{$\begin{array}{l}\text { Money availability to } \\
\text { compliance with }\end{array}$}} \\
\hline & & & & & & & \\
\hline & 25 & 44.6 & 31 & 55,4 & & & \\
\hline Yes & & & & & & & \\
\hline \multicolumn{8}{|l|}{ Physician Inquiries } \\
\hline Adherence & & & & & & & \\
\hline Yes & 123 & 70,3 & 52 & 29,7 & 0,788 & $0,154-4,036$ & 0,775 \\
\hline No & 6 & 75,0 & 2 & 25,0 & & & \\
\hline \multicolumn{8}{|l|}{$\begin{array}{l}\text { Understands about } \\
\text { medicines }\end{array}$} \\
\hline Few/nothing & 92 & 73,6 & 33 & 26,4 & 1,428 & $0,738-2,76$ & 0,289 \\
\hline Excellent & 41 & & 31 & & & & \\
\hline \multicolumn{8}{|l|}{ Respect to patient's } \\
\hline opinion & 67 & 78,1 & 21 & 21,9 & 1,67 & $0,876-3,18$ & 0,118 \\
\hline $\begin{array}{l}\text { Never/eventually } \\
\text { Always }\end{array}$ & 63 & 65,8 & 33 & 34,2 & & & \\
\hline \multicolumn{8}{|l|}{ Respect for } \\
\hline patient's beliefs & 69 & 76,1 & 20 & 23,9 & 1,97 & $1,08-3,817$ & 0,042 \\
\hline $\begin{array}{l}\text { Never/eventually } \\
\text { Alwavs }\end{array}$ & 56 & 65,6 & 32 & 34,4 & & & \\
\hline \multicolumn{8}{|l|}{ Shared goal setting } \\
\hline Never/eventually & 65 & 75,6 & 21 & 24,4 & 1,621 & $0,848-3,098$ & 0,142 \\
\hline Always & 63 & 65,6 & 33 & 34,4 & & & \\
\hline \multicolumn{8}{|l|}{ Satisfaction with } \\
\hline Healthcare & & 8 & & & & & \\
\hline Sometimes/never & 59 & 1,9 & 13 & 18,1 & 2,453 & $1,202-5,005$ & 0,012 \\
\hline Always & 74 & 64,9 & 40 & 35,1 & & & \\
\hline
\end{tabular}

Note: Some questions were not answered, they were considered as missing data. Thus, frequencies not always total the number of subjects included in the sample.

Table 5: Logistic Regression Model of Enabling Factors for Medication Adherence

\begin{tabular}{|c|c|c|c|c|}
\hline Facilitators factors & OR AJUSTED & \multicolumn{2}{|c|}{ Confidences Intervals } & $p$-value \\
\hline Level of Education & 1,1 & 1,034 & 1,294 & 0,011 \\
\hline $\begin{array}{ll}\text { Access } & \text { to } \\
\text { medicines } & \end{array}$ & 4,725 & 2,121 & 10,527 & 0,000 \\
\hline $\begin{array}{ll}\text { Respect } & \text { for } \\
\text { patient's beliefs } & \end{array}$ & 2,326 & 1,022 & 5,294 & 0,044 \\
\hline $\begin{array}{l}\text { Satisfaction with } \\
\text { health services }\end{array}$ & 2,342 & 0,956 & 5,738 & 0,063 \\
\hline
\end{tabular}


Table 6: Asociation of Adherence to Prescribed Medication And Hypertension Control

\begin{tabular}{lccccccc}
\hline \multicolumn{1}{c}{ Adherence } & \multicolumn{2}{c}{ Control $(n=78)$} & Uncontrolled $(n=104)$ & OR & Ic95\% & p-value \\
\hline & Frequency & Percentage & Frequency & Percentage & & \\
\hline Non-adherents & 50 & 38,8 & 79 & 61,2 & 0,565 & $0,296-1,077$ & 0,081 \\
Adherents & 28 & 52,8 & 25 & 57,2 & & & \\
\hline
\end{tabular}

List of REFERENCES

1. Abegaz, T. M., Shehab, A., Gebreyohannes, E. A., Bhagavathula, A. S., \& Elnour, A. A. (2017). Nonadherence to antihypertensive drugs. Medicine, 96(4), e5641. https://doi.org/10.1097/md.000000 0000005641

2. Bosworth, H. B., Granger, B. B., Mendys, P., Brindis, R., Burkholder, R., Czajkowski, S. M., Daniel, J. G., Ekman, I., Ho, M., Johnson, M., Kimmel, S. E., Liu, L. Z., Musaus, J., Shrank, W. H., Buono, E. W., Weiss, K., \& Granger, C. B. (2011). Medication adherence: A call for action. American Heart Journal, 162(3), 412-424. https://doi.org/10.1016/j.ahj. 2011.06.007

3. Burnier, M., \& Egan, B. M. (2019). Adherence in Hypertension. Circulation Research, 124(7), 11241140.

https://doi.org/10.1161/CIRCRESAHA.118.313220

4. Chow, C. K., \& Gupta, R. (2019). Blood pressure control: a challenge to global health systems. The Lancet, 6736(19), 613-615. https://doi.org/10.1016/ s0140-6736(19)31293-0

5. Chow, C. K., Teo, K., Rangarajan, S., Islam, S., Gupta, R., Avezum, A., Bahonar, A., Chifamba, J., Dagenais, G., Diaz, R., Kazmi, K., Lanas, F., Wei, L., Lopez-Jaramillo, P., Fanghong, L., Ismail, N., Puoane, T., Rosengren, A., Szuba, A., ... Yusuf, S. (2013). Prevalence, Awareness, Treatment, and Control of Hypertension in Rural and Urban Communities in High-, Middle-, and Low-Income Countries. JAMA, 310(9), 959. https://doi.org/ 10.1001/ jama.2013.184182

6. Comarca, I. F. de la. (2011). Adherencia al tratamiento farmacológico en patologías crónicas. https://www.euskadi.eus/contenidos/informacion/ce vime infac 2011/es def/adjuntos/infac v19 n1.pdf

7. DEPARTAMENT OF HEALTH AND HUMAN. (2003). Prevention, Detection, Evaluation, and Treatment of. Blood Pressure, 289(19), 52.

8. ESH/ESC. (2013). 2013 ESH/ESC guidelines for the management of arterial hypertension. European Heart Journal, 34(28), 2108-2109. https://doi.org/ 10.1093/eurheartj/eht151

9. Espinosa, V. (2017). La reforma de la reforma en salud. Rev. Panamericana de Salud Pùblica, 41, 449-461.

http://iris.paho.org/xmlui/bitstream/handle/12345678 9/34061/v41a962017.pdf

10. GBD 2017 Risk Factor Collaborators. (2018). Global, regional, and national comparative risk assessment of 84 behavioural, environmental and occupational, and metabolic risks or clusters of risks for 195 countries and territories, 1990-2017: A systematic analysis for the Global Burden of Disease Stu. The Lancet, 392(10159), 1923-1994. https://doi.org/10.1016/S0140-6736(18)32225-6

11. Gosmanova, E. O., \& Kovesdy, C. P. (2015). Adherence to antihypertensive medications: Is prescribing the right pill enough? Nephrology Dialysis Transplantation, 30(10), 1649-1656. https://doi.org/10.1093/ndt/gfu330

12. Khatib, R., Schwalm, J. D., Yusuf, S., Haynes, R. B., McKee, M., Khan, M., \& Nieuwlaat, R. (2014). Patient and healthcare provider barriers to hypertension awareness, treatment and follow up: A systematic review and meta-analysis of qualitative and quantitative studies. PLOS ONE, 9(1), 1-12. https://doi.org/10.1371/journal.pone.0084238

13. Kripalani, S., Yao, X., \& Haynes, R. B. (2007). Interventions to enhance medication adherence in chronic medical conditions: a systematic review. Archives of Internal Medicine, 167(6), 540-550. https://doi.org/10.1001/archinte.167.6.540

14. Krousel-Wood, M. A., Muntner, P., Islam, T., Morisky, D. E., \& Webber, L. S. (2009). Barriers to and Determinants of Medication Adherence in Hypertension Management: Perspective of the Cohort Study of Medication Adherence Among Older Adults. Medical Clinics of North America, 93(3), 753-769. https://doi.org/10.1016/j.mcna. 2009.02.007

15. Krousel-Wood, M., Joyce, C., Holt, E., Muntner, P., Webber, L. S., Morisky, D. E., Frohlich, E. D., \& Re, R. N. (2011). Predictors of Decline in Medication Adherence. Hypertension, 58(5), 804-810. https://doi.org/10.1161/HYPERTENSIONAHA.111.17 6859

16. Lor, M., Koleck, T. A., Bakken, S., Yoon, S., \& Dunn Navarra, A.-M. (2019). Association Between Health Literacy and Medication Adherence Among Hispanics with Hypertension. Journal of Racial and Ethnic Health Disparities, 6(3), 517-524. https://doi.org/10.1007/s40615-018-00550-z

17. MacMahon, S., Alderman, M. H., Lindholm, L. H., Liu, L., Sanchez, R. A., \& Seedat, Y. K. (2008). Blood-pressure-related disease is a global health priority. American Journal of Hypertension, 21(8), 843-844. https://doi.org/10.1038/ajh.2008.223

18. Maimaris, W., Paty, J., Perel, P., Legido-Quigley, H., Balabanova, D., Nieuwlaat, R., \& Mckee, M. (2013). 
The Influence of Health Systems on Hypertension Awareness, Treatment, and Control: A Systematic Literature Review. PLoS Medicine, 10(7). https://doi.org/10.1371/journal.pmed.1001490

19. Marrugat, J., D'Agostino, R., Sullivan, L., Elosua, R., Wilson, P., Ordovas, J., Solanas, P., Cordón, F., Ramos, R., Sala, J., Masiá, R., \& Kannel, W. B. (2003). An adaptation of the Framingham coronary heart disease risk function to European Mediterranean areas. Journal of Epidemiology and Community Health, 57(8), 634-638. https://doi.org/ 10.1136/jech.57.8.634

20. Martínez C., R., Medrano M., S. P., \& Sequeda B., E. L. (2016). Eficacia de intervenciones educativas en la adherencia terapéutica de pacientes hipertensos. Revista Colombiana de Enfermería, 11(12), 55. https://doi.org/10.18270/rce.v11i12.1685

21. McAlister, F. A., Wilkins, K., Joffres, M., Leenen, F. H. H., Fodor, G., Gee, M., Tremblay, M. S., Walker, R., Johansen, H., \& Campbell, N. (2011). Changes in the rates of awareness, treatment and control of hypertension in Canada over the past two decades. CMAJ : Canadian Medical Association Journal = Journal de l'Association Medicale Canadienne, 183(9), 1007-1013. https://doi.org/10.1503/cmaj. 101767

22. Morisky, D. E., Green, L. W., \& Levine, D. M. (1986). Concurrent and Predictive Validity of a Self-reported Measure of Medication Adherence. Medical Care, 24(1), 67-74. https://doi.org/10.1097/00005650198601000-00007

23. Organización Mundial de la Salud. (2004). Adherencia a los tratamientos a largo plazo. Pruebas para la acción. In Ginebra: 2004.

24. Organización Mundial de la Salud. (2013). Información general sobre la hipertension en el mundo. In Organización Mundial de la Salud. https://doi.org/WHO/DCO/WHD/2013.2

25. Parra, D. I., Romero Guevara, S. L., \& Rojas, L. Z. (2019). Influential factors in adherence to the therapeutic regime in hypertension and diabetes. Investigacion y Educacion En Enfermeria, 37(3). https://doi.org/10.17533/UDEA.IEE.V37N3E02

26. Patel, P., Ordunez, P., DiPette, D., Escobar, M. C., Hassell, T., Wyss, F., Hennis, A., Asma, S., \& Angell, S. (2016). Improved Blood Pressure Control to Reduce Cardiovascular Disease Morbidity and Mortality: The Standardized Hypertension Treatment and Prevention Project. The Journal of Clinical Hypertension, 18(12), 1284-1294. https://doi.org/ 10.1111/jch.12861

27. Peacock, E., \& Krousel-Wood, M. (2017). Adherence to Antihypertensive Therapy. Medical Clinics of North America, 101(1), 229-245. https://doi.org/10.1016/j.mcna.2016.08.005
28. Pereira, M., Lunet, N., Azevedo, A., \& Barros, H. (2009). Differences in prevalence, awareness, treatment and control of hypertension between developing and developed countries. Journal of Hypertension, 27(5), 963-975. https://doi.org/ $10.1097 / \mathrm{HJH} .0 \mathrm{~b} 013 \mathrm{e} 3283282 \mathrm{f} 65$

29. Constitución de la República del Ecuador, Pub. L. No. Registro Oficial 449, 216 (2008). https://www.asambleanacional.gob.ec/sites/default/ files/documents/old/constitucion_de_bolsillo.pdf

30. Samb, B., Desai, N., Nishtar, S., Mendis, S., Bekedam, H., Wright, A., Hsu, J., Martiniuk, A., Celletti, F., Patel, K., Adshead, F., McKee, M., Evans, T., Alwan, A., \& Etienne, C. (2010). Prevention and management of chronic disease: A litmus test for health-systems strengthening in lowincome and middle-income countries. In The Lancet (Vol. 376, Issue 9754, pp. 1785-1797). https://doi.org/10.1016/S0140-6736(10)61353-0

31. Steiner, J. F., Ho, P. M., Beaty, B. L., Dickinson, L. M., Hanratty, R., Zeng, C., Tavel, H. M., Havranek, E. P., Davidson, A. J., Magid, D. J., \& Estacio, R. O. (2009). Sociodemographic and Clinical Characteristics Are Not Clinically Useful Predictors of Refill Adherence in Patients With Hypertension. Circulation: Cardiovascular Quality and Outcomes, 2(5), 451-457. https://doi.org/10.1161/ CIRCOUTCOMES.108.841635

32. van der Laan, D. M., Elders, P. J. M., Boons, C. C. L. M., Beckeringh, J. J., Nijpels, G., \& Hugtenburg, J. G. (2017). Factors associated with antihypertensive medication non-adherence: a systematic review. Journal of Human Hypertension, 31(11), 687-694. https://doi.org/10.1038/jhh. 2017.48

33. Zullig, L. L., Stechuchak, K. M., Goldstein, K. M., Olsen, M. K., McCant, F. M., Danus, S., Crowley, M. J., Oddone, E. Z., \& Bosworth, H. B. (2015). Patientreported medication adherence barriers among patients with cardiovascular risk factors. Journal of Managed Care \& Specialty Pharmacy, 21(6), 479485. https://doi.org/10.18553/jmcp.2015.21.6.479

34. Zuo, H.-J., Ma, J.-X., Wang, J.-W., Chen, X.-R., \& Hou, L. (2019). The impact of routine follow-up with health care teams on blood pressure control among patients with hypertension. Journal of Human Hypertension, 33(6), 466-474. https://doi.org/ 10.1038/s41371-018-0158-7 